\title{
Enabling ICT and Knowledge Management to Enhance Competitiveness of Higher Education Institutions
}

\author{
Dwi Sulisworo \\ Dept. of Education Management, Ahmad Dahlan University \\ Jl. Kapas No. 9, Yogyakarta 55164, Indonesia \\ Tel: 62-274-563515Ｅ-mail: dwi@uad.ac.id
}

Received: December 29, 2011 Accepted: February 1, 2012 Published: March 12, 2012

doi:10.5296/ije.v4i1.1207

URL: http://dx.doi.org/10.5296/ije.v4i1.1207

\begin{abstract}
HEIs are recognized to be in the knowledge business, and increasingly they are exposed to marketplace pressures in a similar way to other businesses. In this new situation, knowledge become the main drivers to create growth and security for the organization. The purpose of this paper is to seek the ICT contribution to knowledge management that enhance the HEIs competitiveness. The adoption and use of ICT to facilitate Knowledge Management (KM) has brought to focus the urgent need to come out with new methods, tools and techniques in the development of KM systems frameworks, knowledge processes and knowledge technologies. Creating a shared knowledge base and providing best practices via ICT tools enables the replication of future wellbeing. Through ICT, experts and professionals in different fields are empowered contribute their knowledge to effectively and efficiently.
\end{abstract}

Keywords: Knowledge management, Higher education, Information technology 


\section{Introduction}

Nowadays, in knowledge-based economy land and capital become secondary and knowledge is the primary source of competitiveness and innovation. Higher education is in the knowledge business (Cranfield and Taylor, 2008; Yeh, 2005). Core activities are associated with knowledge creation and dissemination and learning. As a consequence, at the higher education institutions (HEIs), the intangible assets become more important and significantly affect the education quality. As the external environment increased pressure upon HEIs to become more productive and business-like. The HEIs uses the business management techniques as the vehicles for change. HEIs are recognized to be in the knowledge business, and increasingly they are exposed to marketplace pressures in a similar way to other businesses (Kidwell, et. al., 2000: 31) and knowledge become the main drivers to create growth and security for the organization (Aujirapongpan, et. al., 2010). It might, then, be reasonable to suppose that knowledge management (KM) might have something to offer higher education institutions (Rowley, 2000: 327; Yeh, 2005: 36; Suhaimee, et. al., 2005: 48-50; Kidwell, et. al., 2000: 31).

All top management had realized that $\mathrm{KM}$ can be used by HEIs to gain a more comprehensive, integrative, and reflexive understanding of the impact of information on their organizations. The practice of KM, initially derived from theory and practice in the business sector, provides a framework to illuminate and address organizational obstacles around issues of information use and access. HEIs can perhaps learn from KM efforts in the business sector, in terms of the limitations and drawbacks associated with KM. In fact, there are several compelling reasons why HEIs have not, and perhaps should not, simply re-appropriate KM, as popularized by the business sector, into their own organizations. In the business sector, there has focused on information technology and systems as solutions to problems of knowledge transfer and knowledge sharing. In the other hand, HEIs face an increasing number of challenges that have forced them to rethink how they are accountable to external demands, as well as how to improve internal accountability. Rather than focus on micro-level information sharing activities, implementing $\mathrm{KM}$ strategies and practices requires these educational institutions to examine the larger context of information sharing within the organization, specifically how their people, processes, and technology function within it.

KM strategies and practices come to embody the interactions between people, processes, and technology. These three - people, processes, and technology - all function as an integral part of the ongoing dynamics as organizations struggle to meet their information needs. Rather than situating technology as the focal point, KM practices approach technology as an essential resource that is necessary for changes in organizational process to occur, but not sufficient. Recent trends in KM may grant technology disproportionate authority in how organizations share information. However, technology and information systems are neither the driver of information sharing, nor are they tangential to the process. Instead, technology is of equal importance in its ability to impact how information flows throughout an organization. Therefore, KM is the combination of people, processes, and technology that come together to promote a robust system of information sharing, while guiding organizations toward ongoing reflexivity and learning. Technology, including information revolution and globalization, 
continues to exert major effects on knowledge management (KM) development. Considering the challenge and the limitation of KM implementation in HEIs, the purpose of this paper is to seek the map of the interaction between people, processes, and technology to find the optimum solution to improve organizational competitiveness.

\section{Literature Review}

\subsection{Knowledge Management Definition}

As a consequence of knowledge becoming a valuable organisational resource within the business community, there is an increase in organisations' efforts to deliberately manage knowledge in a systematic manner (Pathirage, et. al., 2008). Knowledge Management (KM) is the framework of an integration of organizational elements (Yeh, 2005: 36; ) that selects, distills, stores, organizes, packages, and communicates information essential (Cranfield and Taylor, 2008) to the business of a company in a manner that improves employee performance and corporate competitiveness (Suhaimee, et. al., 2005; Kidwell, et. al., 2000; Bose, 2004). It should be clear that Knowledge Management is fundamentally about a systematic approach to managing intellectual assets and other information in a way that provides the company with a competitive advantage. Knowledge Management is a business optimization strategy, and not limited to a particular technology or source of information. In most cases, a wide variety of information technologies play a key role in a KM initiative, simply because of the savings in time and effort they provide over manual operations. It can be said also that Knowledge management is concerned with the exploitation and development of the knowledge assets of an organization with a view to furthering the organization's objectives.

The knowledge to be managed includes both explicit, documented knowledge, and tacit, subjective knowledge (Harris, 2008; Plessis, 2007). Management entails all of those processes associated with the identification, sharing and creation of knowledge. This requires systems for the creation and maintenance of knowledge repositories, and to cultivate and facilitate the sharing of knowledge and organizational learning. Organizations that succeed in knowledge management are likely to view knowledge as an asset and to develop organizational norms and values which support the creation, and sharing of knowledge (Plessis, 2007; Chong, 2008). Considering the level or the classification of knowledge, there are individual knowledge and organizational knowledge predominantly differentiate each other on the contribution of competitive advantage. In these types of knowledge, individual knowledge wholly resides in the individual employee mind, whereas organizational knowledge generally exists in two forms in any organizations: explicit and tacit knowledge. To learn and acquire new knowledge, individuals should interact and share implicit (tacit) and explicit knowledge with each other (Kamasak and Bulutlar, 2010; Plessis, 2007; Aujirapongpan, et. al., 2010). Explicit knowledge is documentable and sharable through information technologies, whereas tacit knowledge resides in employees' mind, behavior, and perception.

The first major role that knowledge management plays in innovation is enabling the sharing and codification of tacit knowledge. Tacit knowledge sharing is critical for organizations' innovation capability (Plessis, 2007). The resultant employees' knowledge from the 
participation in $\mathrm{KM}$ process is institutionalized as organizational knowledge, which has substantial potential that immensely contributes to competitive advantage. This is the main objective of KM activities.

\subsection{Knowledge Management in Higher Education}

The adoption and use of ICT to enhance and facilitate Knowledge Management (KM) has brought to focus the urgent need to come out with new methods, tools and techniques in the development of KM systems frameworks, knowledge processes and knowledge technologies to promote effective management of knowledge for improved service deliveries in higher education (Omona, et. al., 2010; Yeh, 2005). In general, KM is recognized as a process involving knowledge generation, use, and application. $\mathrm{KM}$ is a process where institutions formulate ways in an attempt to recognize and archive assets from within that are derived from the employees and/or academics of various departments or faculties, and in some cases, even from other institutions and/or organizations (Ramachandran, et. al., 2009; Cranfield and Taylor, 2008). HEIs need to be consciously and explicitly managing the processes associated with the creation of their knowledge assets, and to recognize the value of their intellectual capital to their continuing role in society, and in a wider global marketplace. The term HEIs must embrace all staff and students in the university, and not simply be an additional agenda set by senior management. To be able to effectively manage their knowledge resources, higher education institutions need to have appropriate $\mathrm{KM}$ framework in place. $\mathrm{KM}$ framework refers to integration of organizational knowledge in organizational culture, organizational information technology infrastructure and the organization's store of individual and collective experiences, learning, insights, and values (Omona, et. al., 2010; McNeil, 2011; Ranjan and Khalil, 2007).

Four types of knowledge management objectives as a lens through which to view HEIs i.e. the creation and maintenance of knowledge repositories; improving knowledge access; enhancing knowledge environment; and, valuing knowledge. Interaction, transfer and sharing of knowledge are very much critical to success of any management institution (Ranjan and Khalil, 2007), then the HEIs do not solely provide knowledge to students, but are also engaged in managing and collaborating the existing knowledge for future reference (Ramachandran, et. al., 2009). Several trends will shape the field of knowledge management in the not-too distant future including the HEIs business i.e. Emerging technology solutions, The convergence of knowledge management with e-business, The movement from limited knowledge management projects to more enterprise wide projects, Increasing use of knowledge management to enhance innovation, and Increasing use of tacit knowledge rather than explicit knowledge (Kidwell, et. al., 2000).

\section{Conceptual Model}

By implementing knowledge management, organizations can increase the capability of managing and utilizing their knowledge, and ultimately achieve superior performances. In order for organizations to justify the effectiveness of knowledge management efforts, they have to measure its performance. From the theory and practices that mentioned before, the conceptual model can be figured out as below. 


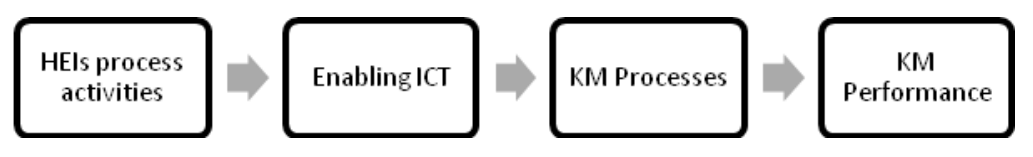

Figure 1: Enabling ICT and KM Relationship

\subsection{HEIs business processes}

The core business processes of the HEIs are divided into six main core processes which are: product development; marketing; registrar activities; teaching and learning; assessment and examination and student activities. The objectives of all these core business processes are to fulfill customer requirements; to obtain customer feedback and to ensure customer satisfaction (Sohail, et. al., 2006).

Core 1 or product development includes the design and development of home programs/courses. The management needs to evaluate the effectiveness or conduct appraisal of the programs offered. At the same time the management needs to carry out a market survey to ensure the programs offered are able to meet customer requirements. Core 2 or Marketing involves all the marketing activities as planned in the marketing calendar. The management needs to conduct surveys on customer perception. Also required of this core process is to measure and analyze the effectiveness of the marketing activities. Core 3 or Registrar covers students' activities such as registration; accommodation; sponsorship; collection of tuition fess and bad debts; sending invoices to sponsorship bodies; releasing academic transcripts; convocation and alumni. Core 4 or Teaching and learning involve all processes linked to delivering knowledge to students. This process requires the management to utilize all the resources such as infrastructure; environment; lecturers; transport; library; computers and science lab to ensure the effectiveness of this process. Core 5 or Assessment and examination include all academic procedures pertaining to continuous assessment and examination. Also, the management needs to carry out statistical analysis on examination results. Core 6 or Student activities emphasis on major students' activities such as annual sports carnival; students' election and students' co-curriculum activities. The activities will be conducted and facilitated by the student council. The Head of Department needs to obtain feedback from students on the effectiveness of the students activities conduced by the student council. A loop among core processes 4, 5 and 6. This indicates the continual improvement activities will always be conducted to ensure the HEIs meets the target of the organization.

\subsection{Enabling ICT}

Creating a shared knowledge base and providing best practices via ICT tools enables the replication of future wellbeing. Through ICT, experts and professionals in different fields are empowered contribute their knowledge to effectively and efficiently (Passerini and $\mathrm{Wu}$, 2008). The enabling ICT is a moderator factor that relates the HEIs processes and the KM processes to achieve the organizational competitiveness as shown by figure 1 . 
Several KM enabling ICT tools and networks were identified to be relevant for developing the proposed framework due to their significance in carrying out KM roles. These include Knowledge Portals, Electronic Document Management Systems, Academic Publishing, Academic Contents and Exchanges, Database Management Systems (DBMS), Data Warehouse, Data Mining, Groupware, Communities of Practices (CoP), Social Communities of Interests, and Individual Communities of Interests (Omona, et. al., 2010). Table 1 shows the KM Enabling ICT Tools from Omona et. al. (2010).

Table 1: KM Enabling ICT Tools/Networks

\begin{tabular}{|c|c|c|}
\hline ICT Tools/Networks & Description of Roles & Examples \\
\hline Knowledge Portals & $\begin{array}{l}\text { Search and access to web-based } \\
\text { knowledge }\end{array}$ & Google, Yahoo, \\
\hline $\begin{array}{l}\text { E-Document } \\
\text { Management Systems }\end{array}$ & $\begin{array}{l}\text { Knowledge repositories created by } \\
\text { individual academic institutions }\end{array}$ & Digital Library \\
\hline Academic Publishing & $\begin{array}{l}\text { Proprietary digital libraries for } \\
\text { electronic access to academic } \\
\text { publishing }\end{array}$ & Emerald, Elsevier \\
\hline $\begin{array}{l}\text { Academic Contents and } \\
\text { Exchanges }\end{array}$ & $\begin{array}{l}\text { Electronic collections of course } \\
\text { materials and learning objects }\end{array}$ & MIT Open Courseware \\
\hline $\begin{array}{l}\text { Database Management } \\
\text { Systems (DBMS) }\end{array}$ & $\begin{array}{l}\text { Set of computer programs that } \\
\text { control the creation, maintenance, } \\
\text { and the use of a database. }\end{array}$ & Student records \\
\hline Data Warehouse & $\begin{array}{l}\text { A repository that facilitates } \\
\text { reporting and analysis of data }\end{array}$ & $\begin{array}{l}\text { Financing data, budgeting } \\
\text { data }\end{array}$ \\
\hline Data Mining & $\begin{array}{l}\text { The process of extracting patterns } \\
\text { from data }\end{array}$ & Academic profiling \\
\hline Groupware & $\begin{array}{l}\text { Is designed to help people involved } \\
\text { in a common task achieve their } \\
\text { goals }\end{array}$ & $\begin{array}{l}\text { Knowledge } \quad \text { Forum, } \\
\text { Synergeia, Wikis }\end{array}$ \\
\hline $\begin{array}{l}\text { Communities of } \\
\text { Practices (CoP) }\end{array}$ & $\begin{array}{l}\text { Groups of practitioners networking } \\
\text { in a particular fields of endeavor to } \\
\text { define a practice and knowledge } \\
\text { domain }\end{array}$ & $\begin{array}{l}\text { Consortia, Educational } \\
\text { Research Services }\end{array}$ \\
\hline $\begin{array}{l}\text { Social Communities of } \\
\text { Interests }\end{array}$ & $\begin{array}{l}\text { Social networks drawn together to } \\
\text { share knowledge and build } \\
\text { relationships }\end{array}$ & Facebook, MySpace, Flickr \\
\hline $\begin{array}{l}\text { Individual Communities } \\
\text { of Interests }\end{array}$ & $\begin{array}{l}\text { Tools for individuals to manage } \\
\text { personal knowledge and networks }\end{array}$ & Blogs, Twitter \\
\hline
\end{tabular}

Source: Omona, et. al. (2010) 


\subsection{Knowledge Management Processes}

$\mathrm{KM}$ process can be divided into four different aspects, i.e. Knowledge acquisition, knowledge creation, knowledge storage, and knowledge application (Bose, 2004; Aujirapongpan, et. al., 2010; Ramachandran, et. al., 2009; Omona, et. al., 2010). Knowledge acquisition is the first process of KM which emphasizes and gives special importance to individual knowledge capability in the organizations. Knowledge acquisition and collection can be derived both from internal knowledge resources, i.e. knowledge about work practices, reports and documents of various knowledge and from external knowledge resources, i.e. environmental data, clients' data, competitors' data and other resources including external benchmarking. A sufficient knowledge database available both quantitatively and qualitatively will positively affect the knowledge acquisition capability.

As already described, knowledge acquisition is a process that covers the activities of the accessibility, collecting and application of acquired knowledge. As knowledge creation is generative, the creation of new knowledge is thus associated with motivation, intuition, expertise and insight that arise in an individual. That means the creation of knowledge must be built from the knowledgeable ones and from lessons learned from the joint experiences of everybody working together in the organizations. Knowledge that has been created should be stored and categorized systematically so that it can be easily and conveniently retrieved, becoming "knowledge retrieval" (Aujirapongpan, et. al., 2010), and appropriate for the dissemination of knowledge. Knowledge to be stored needs "refining" in order to be useful and valuable for the organization; managing such knowledge is arguably the strategic concern for many organization (Pathirage, et. al., 2008). It will work as organizational intelligence and for higher education are used to the competitive advantage of the partner (Rowley, 2000). The final process of $\mathrm{KM}$ is knowledge application, so that it can be of value to the organizations: it can make the organizations attain the effectiveness of KM. This also implies knowledge transfer and knowledge utilization (Yeh, 2005; Ranjan and Khalil, 2007). Knowledge transfer can be undertaken in many ways, officially or unofficially, i.e. through various media, conferences, study tours, change of positions or duties, supervising-system, and teamwork (Ranjan and Khalil, 2007; Omona, et. al., 2010).

\subsection{Knowledge Management Performance}

Knowledge is considered an important resource of organizations, which will help build competitive advantage (Aujirapongpan, et. al., 2010). Most of the literature connect the success of KM effectiveness with the result of organizational performance, which can be concluded into three aspects: efficiency, adaptability and innovativeness. One benefit from $\mathrm{KM}$ effectiveness is economic efficiency in the organizations. That means it lowers costs and increases productivity (Aujirapongpan, et. al., 2010). The latter is especially obvious if KM effectiveness is effective and efficient in saving time in information and knowledge finding, and time in working while efficiently utilizing technology, co-operation and team-working. the HEIs cannot underestimate the role of information technology (IT) in enabling KM. While knowledge sharing depends on people, many other KM processes need the support of IT infrastructure (Ramachandran, et. al., 2009). If less time and effort is spent, all else being 
equal, the organization should become more efficient. Given the constantly changing competition environment, i.e. rapid technological change, diverse needs of the consumers and increasing global market, including changes in population, official rules and regulations, and new technology that affect the organizations, to survive, organizations must be responsive to those changes by having the capability of adaptability: the capability to adapt to the attitudes, culture, technology and structure of the organizations appropriate to changes so that the environmental impacts will not be obstacles to the development of the organizations. For the organizations to be able to adapt, knowledge of the changing environment and the impacts on their organizations is needed. Knowledge management allows easy access to expertise and know-how, whether it is formally recorded or in someone's mind. Knowledge management further allows collaboration, knowledge sharing, continual learning and improvement (Plessis, 2007) and encourage the organizations to acquire change and efficiently use knowledge application to solve the problems and come up with creative and innovative solutions (Chong, 2006). With effective KM processes, the organization will have the knowledge about how to change and make efforts to adapt to the environment changing. That is, the adaptability capability of the organization resulting from effectiveness of KM.

Knowledge integration via knowledge management platforms, tools and processes must therefore facilitate reflection and dialogue to allow personal and organizational learning and innovation (Plessis, 2007). The effectiveness of KM will help supporting innovation in the organizations. Therefore, innovativeness, which means product innovation, process innovation, implemental innovation, radical innovation, technology or administrative innovation that occurred in the organizations are indicators of effective KM. Considering the element of the system that has been described previously, the conceptual model can be detailed as shown by figure 2 below.

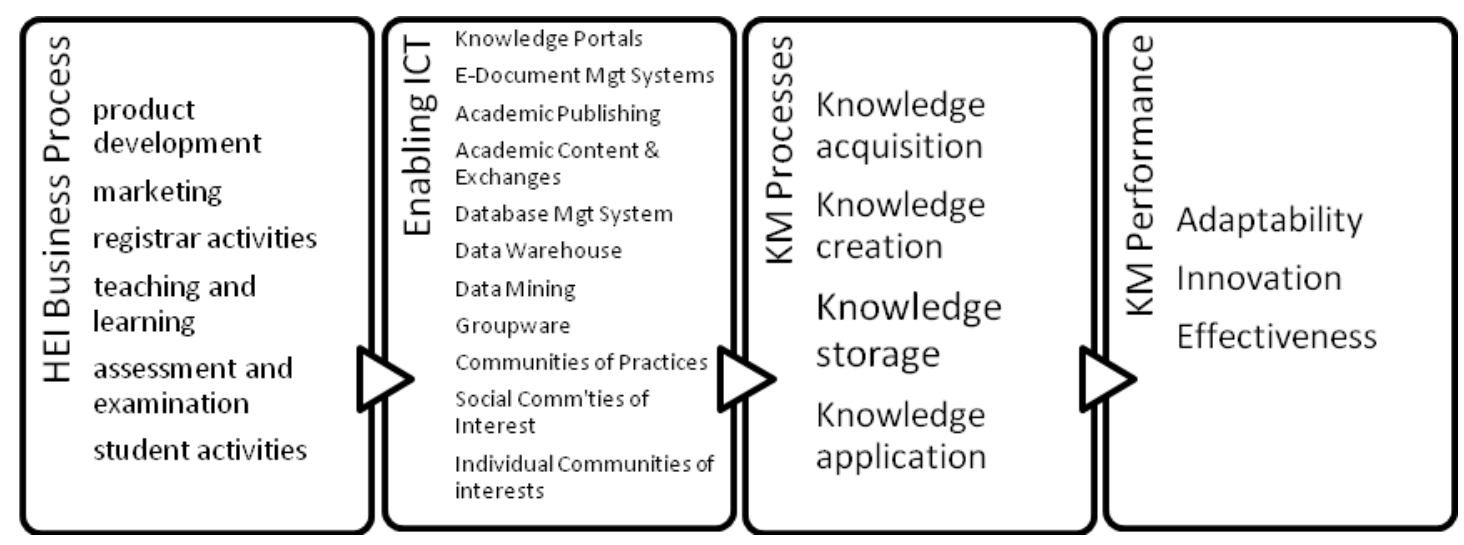

Figure 2: The model of ICT and KM to Enhance Competitiveness

\section{Conclusion}

KM framework refers to integration of organizational knowledge in organizational culture, organizational information technology infrastructure and the organization's store of individual and collective experiences, learning, insights, and values. Knowledge integration via knowledge management platforms, tools and processes must therefore facilitate reflection 
and dialogue to allow personal and organizational learning and innovation. The effectiveness of KM will help supporting innovation in the organizations. Therefore, innovativeness, which means product innovation, process innovation, implemental innovation, radical innovation, technology or administrative innovation that occurred in the organizations are indicators of effective KM. The enabling ICT is a moderator factor that relates the HEIs processes and the KM processes to achieve the organizational competitiveness. Several KM enabling ICT tools and networks were identified to be relevant for developing the proposed framework due to their significance in carrying out KM roles.

\section{References}

Aujirapongpan, S., Vadhanasindhu, P., Chandrachai, A., and Cooparat, P. (2010). Indicators of knowledge management capability for $\mathrm{KM}$ effectiveness. VINE: The journal of information and knowledge management systems, 40 (2), 183-203.

Bose, R. (2004). Knowledge management metrics. Industrial Management \& Data Systems, 104 (6), 457-468. http://dx.doi.org/10.1108/02635570410543771

Chomsky, N., Halle, M., \& Harris, Z. (1960). Toward a generative model of Pig Latin syntax. Pigology: Current issues in Pig Latin research, 26 (2), 247-289.

Chong, S.C. (2006). KM critical success factors A comparison of perceived importance versus implementation in Malaysian ICT companies. The Learning Organization, 13 (3), 230-256. http://dx.doi.org/10.1108/09696470610661108

Cranfield, D.J., and Taylor, J. (2008). Knowledge Management and Higher Education: A UK Case Study. The Electronic Journal of Knowledge Management, 6 (2), 85 - 100.

Harris, R.J. (2008). Developing a collaborative learning environment through technology enhanced education (TE3) support. Education+ Training, 50 (8), 674-686.

Kamasak, R., and Bulutlar, F. (2010). The influence of knowledge sharing on innovation", European Business Review, 22 (3), 306-317. http://dx.doi.org/10.1108/09555341011040994

Kidwell, J. J., Linde, K.M., and Johnson, S.L. (2000). Knowledge management practice in higher education. Educause Quarterly, 4, 28-33.

McNeil, R. (2011). Application of Knowledge Management for Sustainable Development in Institutions of Higher Education. Dalhousie Journal of Interdisciplinary Management, 7 (Spring), 1-13.

Omona, W., van der Weide, T., and Lubega, J. (2010). Using ICT to enhance Knowledge Management in higher education: A conceptual framework and research agenda. International Journal of Education and Development using Information and Communication Technology (IJEDICT), 6 (4), 83-101.

Passerini, K., and Wu, D. (2008). The new dimensions of collaboration: mega and intelligent communities, ICT and wellbeing. Journal of Knowledge Management, 12 (5), 79-90. http://dx.doi.org/10.1108/13673270810902957 


\section{Macrothink}

International Journal of Education

ISSN 1948-5476

2012, Vol. 4, No. 1

Pathirage, C., Haigh, R., Amaratunga, D., and Baldry, D. (2008). Knowledge management practices in facilities organisations: a case study. Journal of Facilities Management, 6 (1), 5-22. http://dx.doi.org/10.1108/14725960810847431

Plessis, M. (2007). The role of knowledge management in innovation. Journal of Knowledge Management, 11 (4), 20-29. http://dx.doi.org/10.1108/13673270710762684

Ramachandran, S.D., Chong, S.C., and Ismail, H. (2009). The practice of knowledge management processes: A comparative study of public and private higher education institutions in Malaysia. VINE: The journal of information and knowledge management systems, 39 (3), 203-222.

Ranjan, J., \& Khalil, S. (2007). Application of Knowledge Management in Management Education: A Conceptual Framework. Journal of Theoretical and Applied Information Technology, 3 (3), 15-25.

Rowley, J. (2000). Is higher education ready for knowledge management? The International Journal of Educational Management, $14 \quad$ (7), 325-333. http://dx.doi.org/10.1108/09513540010378978

Sohail, M.S., Daud, S., \& Rajadurai, J. (2006). Restructuring a higher education institution: A case study from a developing country. International Journal of Educational Management, 20 (4), 279-290. http://dx.doi.org/10.1108/09513540610665397

Suhaimee, S., Abu Bakar, A., \& Alias, R.A. (2005). Knowledge Management Implementation in Malaysian Public Institution of Higher Education. Proceedings of the Postgraduate Annual Research Seminar 2005, 27-51.

Yeh, Y.M. (2005). The Implementation of Knowledge Management System in Taiwan's Higher Education. Journal of College Teaching \& Learning, 2 (9), 35-42.

\section{Copyright Disclaimer}

Copyright reserved by the author(s).

This article is an open-access article distributed under the terms and conditions of the Creative Commons Attribution license (http://creativecommons.org/licenses/by/3.0/). 